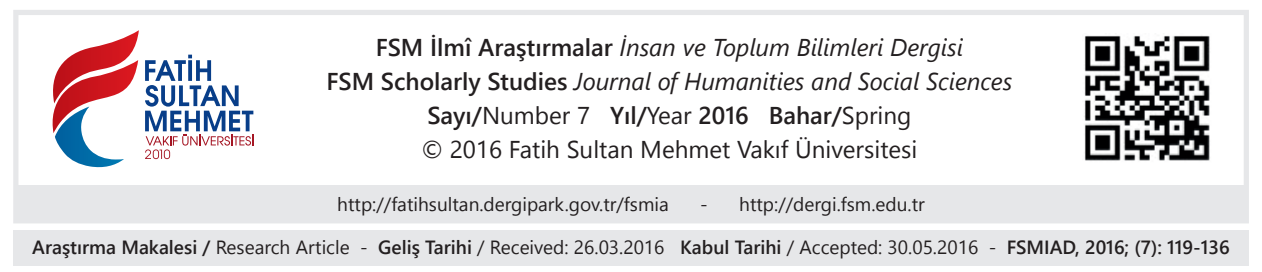

\title{
İstanbul Şehir Adının Telaffuzunun Tarihî Süreç İçinde Gelişmesi
}

Yavuz Kartallığlu*

$\ddot{\mathbf{O z}}$

İstanbul adının Osmanlı Türkçesi döneminde nasıl telaffuz edilmiş olduğu Arap harfli metinlerden değil Latin harflerinin de kullanıldı̆̆g, kelimenin ünlü ve ünsüzlerinin açıkça kaydedildiği çeviri yazılı metinler aracılığı ile tespit edilebilir. İstanbul adı Grekçe stambóli stembóli $(n) \sim$ stimbóli(n) şekillerinden Osmanlı Türkçesine Stambol şeklinde geçmiş ve Osmanlılar arasında 15 farklı şekilde telaffuz edilmiştir. Bu kadar farklı telaffuzun ortaya çıkmasında ön seste ünlünün bulunup bulunmaması, ب harfinden önceki ن’nin durumu ve son hecedeki ünlünün geniş veya dar olarak telaffuz edilmesi belirleyici olmuştur. Bu makalede 38 çeviri yazılı metinde İstanbul kelimesinin Osmanlı Türkçesi boyunca nasıl telaffuz edilmiş olduğu ve Türkçeleşme süreci incelenmiştir.

Anahtar Kelimeler: Stambol, İstambol, İstanbul, telaffuz, Osmanlı Türkçesi.

\section{Pronunciational Development of İstanbul City Name in Historical Process}

\section{Abstract}

The way how İstanbul noun was pronounced in Ottoman Turkish period can be detached through transcription texts in which the vowels and consonants of the words were recorded explicitly in Latin letters, not through the texts written in Arabic script. The

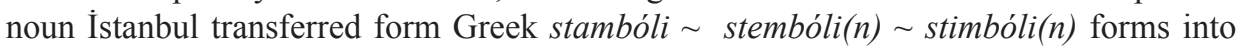
Ottoman Turkish and was pronounced with 15 different forms by Ottomans. The decisive reason for these different pronunciations are whether there is a vowel in the beginning position, the situation of $\dot{u}$ and $\dot{ }$ before pronunciation of the final vowel as rounded or unrounded. In the present article the way how İstanbul noun was pronounced during Ottoman Turkish period and their process of becoming Turkish elements are analyzed in 38 transcription texts.

Keywords: Stambol, İstambol, İstanbul, pronunciation, Ottoman Turkish.

* Doç. Dr., Gazi Üniversitesi Edebiyat Fakültesi Çağdaş Türk Lehçeleri ve Edebiyatları Bölümü, Ankara/Türkiye, yavuzkartalligolu@gmail.com 


\section{İstanbul Adının Kökeni}

İstanbul adının kökeni ile ilgili etimoloji denemeleri 19. yüzyılın sonunda başlar. ${ }^{1}$ Berberian, daha önceki araştırmaların verilerine göre İstanbul adının kökenini iki maddede toplar: 1. Stanbol Grekçe eis tin polin /istinpolin/ veya stin poli, yani "şehirde" kelimesinin bozulmuş şeklidir. 2. Stanbol Grekçe Konstantinapolis'in bozulmuş şeklidir. ${ }^{2}$ Berberian'a göre Konstantinapolis adının İstanbul şeklini aldığı görüşü eskidir ve çok kabul görmemektedir, genel kabul İstanbul adının eis tin polin veya stin poli' nin değişik varyantı olduğudur. ${ }^{3}$

İstanbul adının etimolojisi ile ilgili son ve en önemli araştırma Marek Stachowski ve Robert Woodhouse'a aittir. Onlara göre İstanbul adının kökü günlük konuşma diline ait Orta Çağ Grekçesindeki $\sigma \tau \eta v ~ \Pi o ́ \lambda t(v) / s t i n$ Póli(n)/'dir. Kökün anlamı da büyük bir ihtimalle "İstanbul'da"dır, muhtemelen "İstanbul'a, İstanbul'un içine"dir. ${ }^{4}$ Problemin büyük bir kısmını oluşturan ve zor açıklanan -stin morfemi ile ilgili Stachowski ve Woodhouse şu tespitlerde bulunurlar: "Birinci unsurun üç varyantı -stin, -sten, -stan 20. yüzyılın başlarına kadar Anadolu'nun çeşitli bölgelerinde duyulmuştur. ${ }^{5}$-staN- hecesinin ünlü sistemi, büyük bir olasıl1kla Tsakonian *staN bol biçiminin devam etmesine veya itacistic *stiN bol'un Türkçe düzelme gösterebilmesine rağmen etacistic *steN bol'dan Türkçe ünlü uyumu arac1lığıyla türemiştir. -bul'un ünlü sistemi tamamen Türkçedir."6 Stachowski ve Woodhouse kelimenin ilk parçasını Grekçeye dayandırırlar, -bul kısmı Türkçenin ses özellikleri sonucu oluşan şekildir; ön sesindeki i, ilk seste ünsüz yığılmasını engelleyen Türkçe bir ön türemedir. ${ }^{7}$ Stachowski ve Woodhouse, Grekçe şekillerin Türkçeye geçişini şöyle göstermişlerdir:

Çağdaş Türkçe: Ístanbul < Osmanlı Türkçesi: Stambol ( 14. yüzyıl Astanbul $)<$ Ortaçağ Grekçesi (Tsakonian, Marmara Denizi’nin güney kıyısında:) stambóli (diğer lehçelerde:) stembóli(n) stimbóli(n), yazı dilinde 'İstanbul'da,

1 Kelimenin etimolojisi ile ilgili çalışmalar için şu iki makale önemlidir: H. Berberian, "Stanbol (İstanbul) Kelimesinin Etimolojisine Dair Bir Deneme", İktisat Tarihi Dergisi, 6/9, 1954, s. 187-192, Marek Stachowski-Robert Woodhouse, "The Etymology of İstanbul: Making Optimal Use of the Evidence”, Studia Etymologica Cracoviensia, Krakov, vol. 20, 2015, s. 221-245.

2 Berberian, a.g.m., s. 187

3 Berberian, a.g.m., s. 188. Berberian, makalesinde verdiği örneklerle İstanbul kelimesinin Ermenice üzerinden Türkçeye geçtiğini ispatlamaya çalışır (bk. Berberian, a.g.m., s. 190).

4 Stachowski-Woodhouse, a.g.m., s. 240

5 Stachowski ve Woodhouse'un verdiği bu bilgiyi Pihan vasıtasıyla doğrulamak mümkündür. Pihan İstanbul kelimesini Arap harfleri ile استانبول, Latin harfleri ile Stamboul = Stambul şeklinde kaydeder (bk. A. P. Pihan, Glossaire des mots Français tires de l'arabe, du Persan et Turc, Paris, 1847, s. 262). Arap harfli kayıt imlayı, Latin harfli kayıt ise telaffuzu gösterir. Ayrıca Besse ve Chodzko'da Stambol telaffuzu vardır. 19. yüzyılda kelime hâlâ Stambol ve Stambul olarak da telaffuz edilebilmektedir.

6 Stachowski-Woodhouse, a.g.m., s. 240

7 Stachowski-Woodhouse, a.g.m., s. 240 
İstanbul'a, İstanbul'un içine' < stan Póli( $n) \sim$ sten Póli $(n)^{8}$ (> Arapça /al-Masudi, 10. yüzyı1/ stan būlin 'İstanbul') $\sim$ stin Póli $(n)<$ Grekçe günlük konuşma dilinde: $s^{-}$' '1. +A; 2. +DA; 3. +A doğru' + tan $\sim$ ten $\sim$ tin, tanımlık + Póli(n), belirtme hâli $<$ Pólis, yazı dilinde 'şehir', örnek olarak 'İstanbul'. ${ }^{9}$ Stachowski ve Woodhouse, bu açıklamaları ile İstanbul adının Kostantinópoli veya Kostantínu póli şekillerinden geldiği görüşünü aslında bertaraf etmiş olurlar. ${ }^{10}$

\section{Osmanlı Türkçesinde İstanbul Adı}

Anadolu Selçukluları ve Osmanlıların ilk devirlerine ait bazı kaynaklarda şehrin ad1 استنبول (İstinbol, İstanbol veya İstanbul) imlasiyla yazılırken ${ }^{11} 12$. yüzyıla ait bir Ermeni kaynağında Stambol tabiri geçer. ${ }^{12}$

Osmanlı Türkçesinde İstanbul adı genel olarak استنانبول şeklinde yazılmıştır. Arap harfli şekillerin Osmanlı Türkçesinde hangi dönemde nasıl telaffuz edildiği konusunda bir inceleme yoktur. Kelimenin etimolojisi dışında ilk hecenin /i/ ile mi yoksa /1/ ile mi telaffuz edilmiş olduğu veya telaffuz edilmesi gerektiği delile dayanmayan popüler bir tartışmadır. Delile dayalı bir inceleme, yani kelimenin Osmanlı Türkçesi döneminde nasıl telaffuz edildiği, sadece hem Arap hem de Latin harflerinin kullanıldı $\breve{g} 1$ ve $/ 1 /, / \mathrm{i} / ; / \mathrm{n} /, / \mathrm{m} / ; / \mathrm{u} /, / \mathrm{o} /$ seslerinin açıkça belirtildiği çeviri yazılı metinler vasıtası ile yapılabilir.

Stachowski ve Woodhouse Orta Çağ Rumcasındaki stambóli stembóli(n) stimbóli(n) şekillerinin Osmanlı Türkçesine Stambol olarak geçtiğini ortaya koymuşlardır. Bu makalede Osmanlı Türkçesindeki Stambol şeklinin İstanbul şeklini alış süreci ve tarihî telaffuzu 1553-1921 yılları arasında hem sadece Latin hem de Arap-Latin harfleri ile yazılmış olan gramer ve sözlükler aracılığı ile tespit edilmeye çalış1lacaktır. Bunun için veriler 1, i; n, m; u, o gibi seslerin birbirinden açıkça ayrılarak kaydedildiği çeviri yazılı metinlerden -Parigi hariç- alınmıştır.

\section{İnceleme}

İncelemenin esası olan İstanbul adının telaffuzu üç farklı noktada çeşitlilik göstermekte ve bir sorun oluşturmaktadır:

8 Kelimenin ilk kaydıyla ilgili şu bilgi önemlidir: 10. yüzyılda Arap bir yolcu tarafından tutulan en eski kayıt, neredeyse etacistic $\sigma \tau \varepsilon v$ Пó $\imath$ vv sten Póli(n)'den başka bir şekilde yorumlanamaz (bk. Stachowski-Woodhouse, a.g.m., s. 40).

9 Stachowski-Woodhouse, a.g.m., s. 240

10 Şemseddin Sami de Kamus-ı Türki'de kelimenin kökenini eis tin polin şeklinde Rumca kaydı ile gösterir (bk. Paşa Yavuzarslan, Şemseddin Sami Kamus-ı Türki, TDK, Ankara, 2010, s. 530).

11 Halil İnalckk, “İstanbul”,TDVIA, c.23,İstanbul, 2001, s. 220.

12 Ani'li Samuel'e dayanarak Berberian, İstanbol veya İstanpol şekillerinin Ermenice'de 11. yüzyıldan beri mevcut olduğunu belirtir (Berberain, a.g.m., s. 190). 
1. Ön sesteki ünlünün durumu: $\varnothing$, i, $1(?) ;{ }^{13}$

2. ب̈̈nsüzünden önceki u’nin durumu: n, m (?);

3. son hecedeki ünlünün durumu: $\mathrm{o}, \mathrm{u}, 1$ (?).

İstanbul adının telaffuzu çeviri yazılı metinlerde yüzyıllara göre şöyle kaydedilmiştir:

\section{5. yüzyıl}

Johannes Schiltberger'e göre 15. yüzyılın başında Rumlar şehre /İstimboli/, Türkler ise /Stampol/ demekte idiler. ${ }^{14}$

15. yüzyılda İstanbul adı asli şekline yakın olarak telaffuz edilmiştir.

\section{6. yüzyıl}

Filippo Argenti (1533)'de ${ }^{15}$ kelime sadece Latin harfleri ile /tambol/Stambol/ olarak kaydedilmiştir.

Bartholomeo Georgieviz (1553)' $\mathrm{de}^{16}$ kelime Latin harfleri ile stambol /Stambol/şseklindedir.

16. yüzyılda kelime ön seste ünlü olmadan, /b/ sesinden önce $/ \mathrm{m} /$ 'li olarak ve ikinci ünlüsü asli şekline uygun, /u/ yerine /o/ ile telaffuz edilmiştir. Argenti ve Georgieviz'in kayıtları İnalcık'ın daha önce vermiş olduğu bilgiyi doğrulamaktadır; 16. yüzyıldaki yaygın telaffuz, özgün şekle en yakın olan Stambol ${ }^{17}$ telaffuzudur.

\begin{tabular}{|c|c|c|}
\hline 16. yüzyıl & Arap harfli imla & Telaffuz \\
\hline Argenti & - & Stambol \\
\hline Georgieviz & - & Stambol \\
\hline
\end{tabular}

13 Stachowski ve Woodhouse, i'li şeklin modern Türkçe telaffuzu gösterdiğini, 1'lı şeklin ise Türkçenin ünlü uyumu sebebi ile meydana geldiğini kaydederler (bk. Stachowski-Woodhouse, a.g.m., s. 222).

14 Johannes Schiltberger, Als Sklave im Osmanischen Reich und bei den Tataren: 1394-1427, Türkler ve Tatarlar Arasında, (çev. Turgut Akpınar), İstanbul, 1997, s. 175.

15 Milan Adamoviç, Floransalı Filippo Argenti’nin Notlarına Göre (1533) 16. Yüzyıl Türkçesi, (çev. Aziz Merhan), Ankara, TDK, 2009, s. 237.

16 Bartholomeo Georgieviz, De Turcarum Moribus Epitome, Apvd Ioan Tornaesivm, Lvgdvni, 1557, s. 69.

$17 \mathrm{Bu}$ telaffuz çeviriyazılı metinlerden tanıklanabilen şekildir. Çeviriyazılı metinlerden önce yazılmış bazı Osmanlı Türkçesi metinlerinde استنبول şekli vardır. Mesela, 15. yüzyılda yazılmış olan Tevârîh-i Âl-i Osmân'da (bk. Kemal Yavuz-M. A. Yekta Saraç, Âşık Paşazade Osmanoğulları'nın Tarihi, Koç Kitaplığı, İstanbul, 2003) kelime استنتبول şeklinde geçer. Bu imla, telaffuzla ilgili kesin bilgi vermez. 


\section{7. yüzyıl}

Pietro Ferraguto (1611)'da ${ }^{18}$ kelime Latin harfleri ile stamból /Stambol/ şeklindedir. Rocchi bu telaffuzun eski Osmanlı'da yaygın, popüler bir kullanım olduğunu belirtmiştir. ${ }^{19}$

Hieronymo Megisero (1612)' $\mathrm{da}^{20}$ kelime sadece Latin harfli olarak geçer: stambol /Stambol/.

Giovanni Molino (1641)' $\mathrm{da}^{21}$ kelime Latin harfleri ile Isdambol /I(I)sdambol/ şeklinde kayıtlıdır. Molino, ön seste ünlüyü kaydetmiştir ama bu imladan ünlünün i mi 1 mı olduğunu anlamak zordur.

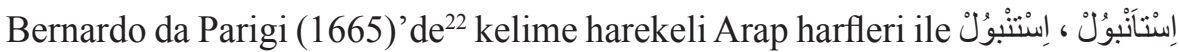
şeklinde kaydedilmiştir. Bu imladan kelimenin nasıl telaffuz edildiği açıkça belli olmasa da ön seste /i/ veya /1/ ünlüsünün bulunduğu bellidir.

Jakab Nagy de Harsany (1672)' $\mathrm{de}^{23}$ kelime Latin harfleri ile stambol /Stambol/ olarak geçer.

Antonio Mascis (1677)'te ${ }^{24}$ kelime sadece Latin harfleri ile Iftanbul /I(I)stanbul/ şeklindedir.

Mesgnien Meninski (1680)'de ${ }^{25}$ kelimenin hem Arap hem de Latin harfleri ile farklı kayıtları vardır; Arap harfli kayıtlar imlayı gösterirken, Latin harfli kayıtlar o dönemdeki telaffuzu için çok önemli bir delildir. Arap harfli kayıtlar sşeklinde iken Latin harfli kayıtlar, yani telaffuzlar şöyle kaydedilmiştir: iftāmbol /İstambol/, iftanbol /İstanbol/, İslāmbol /İslambol/. ${ }^{26}$

18 Luciano Rocchi, Il "Dittionario della Lingua Turchesca" di Pietro Ferraguto (1611), Trieste, Edizioni Universita di Trieste, 2012, s.71.

19 Rocchi, a.g.e., s. 101.

20 Hieronymo Megisero, Institutionum Lingva Tvrcica, Leipzig, 1612, s. 112.

21 Ewa Siemieniec-Golaś, Turkish Lexical Content in "Dittionario Della lingua Italiana, Turchesca” by Giovanni Molino (1641), Kraków, 2005, s. 131.

22 Yavuz Kartallığlu, Söz Kitabı Türkçe-İtalyanca Sözlük, Bernardo da Parigi, TDK, Ankara, 2015, s. 489.

23 George Hazai, Das Osmanisch-Türkische im XVII. Jahrrhundert Untersuchun-gen an den Transkriptionstexten von Jakab Nagy de Harsany, Akademiai Kiado, Budapest, 1973, s. 276.

24 Antonio Mascis, Vocabolario Toscana e Turchesco, Florence, 1677, s. 35.

25 F. M. Meninski, Thesaurus Linguarum Orientalium, Turciace, Arabiace, Persiace Lexicon, c. I, Stanislaw Stachowski-Mehmet Ölmez, Simurg, İstanbul, 2000, 178, s. 205.

26 İslambol, “İslam'ın bol olduğu yer, İslam ile dolu” anlamında bir halk etimolojisidir ve muhtemelen bu şekil de ilk olarak Meninski'de geçer (Stachowski-Woodhouse, a.g.m., 221). Meninski ile aynı yüzyılda yazılmış olan Evliya Çelebi'nin Seyahatnamesi'nde de Lisân-ı Âl-i Osmâniyânda İslâmbol derler (bk. Robert Dankof, Seyit Ali Kahraman, Yücel Dağlı, Evliya Çelebi Seyahatnâmesi, 1. kitap, Yapı Kredi Yayınları, İstanbul, 2006, s. 14) açıklaması vardır. Halk etimolojisine dayalı bu şekil de 17. yüzyılda yaygın bir telaffuzdur. 
Bu yüzyılda kelimenin Arap harfli imlasında bütün ünlülerin harf ile gösterildiği ve /a/ ünlüsünün harf ile gösterilmediği iki yazılış vardır: استانبول،استنبول İslambol şeklinde ise bütün ünlüler gösterilmiştir.

17. yüzyılın genelinde de $S \operatorname{sambol}^{27}$ telaffuzu hâkimdir fakat kelime Molino tarafından İ/Isdambol şeklinde ön seste ünlü ile kaydedilmiştir; bu çeviri yazılı metinlere yansıyan ilk ön ünlülü telaffuzdur. Ön sesteki ünlünün /i/ olduğunu Meninski kaydetmiştir. ب'den önceki ünsüzün telaffuzu ile ilgili Meninski Latin harfleri ile İstanbol şeklini kaydetse de bu yüzyılda da genel telaffuz ب'den önce $/ \mathrm{n} /$ ile değil /m/ iledir. Íslambol şekli ilk olarak Meninski'de geçer. Bu yüzyılda kelimenin son hecesi yaygın olarak asli o ünlüsü ile telaffuz edilir fakat Mascis'in son hecenin /u/ ile de telaffuz edildiği kaydı, /o/ > /u/ değişiminin ilk kaydıdır; /u/'lu telaffuzun -başka daha erken tarihli bir kayıt bulununcaya kadar- 17. yüzyılda başladığı söylenebilir.

17. yüzyılda Stambol telaffuzunun yaygın telaffuz şekli olduğunu yine 17 . yüzyılda İstanbul'a gitmiş olan yabancı seyyahlardan da doğrulamak mümkündür. Josephus Grelot, Türklerin şehre Stambol dediklerini belirterek kelimenin kökeni ile ilgili önemli bir bilgi vermiştir: Bu ad belki de kent çevresindeki Rumlara, yolda "Nereye gidiyorsun?" diye sorulduğunda verdikleri cevap olan "Eis ten polin" । şehre/ sözlerinin bozulmasindan türemiştir. Türkler ve diğer levantenler de gerçek kökenini bilmezler. Şu hâlde kentin eskiden "Konstantinopolis" bugün ise iman bolluğunu belirten "Stambol" adıyla tanındığını söylemek yeterlidir. ${ }^{28}$ George Wheler da şehrin Stambol olarak telaffuz edildiğini, kelimenin aslının Íslambol olduğunu kaydetmiştir. ${ }^{29}$ Jean du Mont da kelimeyi Stambol olarak yazmıştır. ${ }^{30}$

\begin{tabular}{|c|c|c|}
\hline 17. yüzyıl & Arap harfli imla & telaffuz \\
\hline Ferraguto & - & Stambol \\
\hline Megisero & - & Stambol \\
\hline Molino & - & $\dot{\mathrm{I}} /$ Isdambol \\
\hline Parigi & 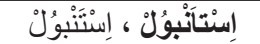 & - \\
\hline Harsany & - & Stambol \\
\hline Mascis & - & $\dot{\mathrm{I}} /$ Istanbul \\
\hline Meninski & استنامبول & $\begin{array}{l}\text { İslambol } \\
\text { İstanbol } \\
\text { İstambol }\end{array}$ \\
\hline
\end{tabular}

27 Nedim Divanı'nda hem Stanbul hem de İstanbul şekli vardır (bk. Muhsin Macit, Nedim Divanı, ekitap, Kültür Bakanlığı, 2012, s. 21). 17. yüzyılda bu iki kelimenin telaffuzu Stambol, Istambol olmalidir.

28 Josephus Grelot, Istanbul Seyahatnamesi, (çev. Maide Selen), Pera Turizm ve Ticaret AŞ, Alâattin Eser Kitaplığı Yayınları, İstanbul, 1998, s. 62.

29 George Wheler, A Journey into Greece 1675-1676, London, 1682, s. 178.

30 Jean du Mont, A New Voyage to the Levant 1690-1691, London, 1696, s. 145. 


\section{8. yüzyıl}

Thomas Vaughan (1709)'da ${ }^{31}$ kelime Latin harfleri ile iftanból /İstanbol/şseklindedir.

Johannes Christianus Clodius (1730)'ta ${ }^{32}$ kelime Arap harfleri ile استانبول şeklinde iken telaffuz il tambol /İstambol/ olarak kaydedilmiştir.

Jean Baptiste Holderman (1730)'ta ta kelime Arap harfleri ile استانبول'seklindedir ve telaffuzu Iftanbol/İstanbol/'dur.

Pierre François Viguier (1790)' de ${ }^{34}$ kelimenin sadece Latin harfli kayıtları vardir: Eftambel /Istamb11/, eftanbel /Istanb11/, eftambol /Istambol/, eftanbol/Istanbol/, eftamboul /Istambul/, eftanboul/Istanbul/, Islambol/İslambol/, İslamboul / Islambul/. Viguier'nin kayıtlarında sekiz farklı telaffuz vardır. İstanbul adının ilk /1/'lı şeklinin kaydedildiği tarih 1790'dır. Kelimenin son hecesindeki /o/ ünlüsü ilk defa /u/'ya, hatta /1/'ya dönüşmüş olarak kaydedilmiştir. Yani -bol hecesinin 18. yüzyılda artık -bul şeklinde yaygın olarak telaffuz edildiğini Viguier'in kayıtlarından tespit etmek mümkündür. Bunu, Íslambol şeklinin İslambul olarak kaydedilmiş olması da desteklemektedir.

Joseph von Preindl (1791)'da ${ }^{35}$ Latin harfleri ile Stambol/Stambol/ olarak yazılmış, telaffuzda st- ünsüzlerinin önünde i'nin türetildiği bilgisi verilerek telaffuzun Iftambol /İstambol/ şeklinde olduğu kaydedilmiştir.

Cosimo Comidas de Carbognano (1794)'da da Arap harfli şekil استانبول, Latin harfli şekil Ystambol/Istambol/'dur.

Bu yüzyılda kelimenin Arap harfli imlasında bütün ünlüleri harf ile gösterilmiştir.

18. yüzyılın başlarında İstanbol ve İstambol telaffuzları hâkimdir. Viguier, döneminde kelimenin sekiz farklı telaffuzu olduğunu göstermiştir. Ön seste 1 ünlüsü ilk olarak Viguier'de vardır, sonra Carbonano'da aynı kayıt görülür. Viguier ve Carbognano'nun Osmanlı Türkçesi telaffuzları ile ilgili en doğru bilgiler veren nadir eserlerden ${ }^{37}$ olduğu göz önünde bulundurulursa bu yüzyılda /1/'l1 telaffuz en

31 Thomas Vaughan, A Grammar of the Turkish Language, London, 1709, s. 77.

32 Johannes Christianus Clodius, Compendiosum lexicon latino-turcico-germanicum, Leipzig, 1730, s. 744.

33 Jean Baptiste Daniel Holderman, Grammaire Turque, Constantinople, 1730, s. 117.

34 Pierre François Viguier, Élémens De La Langue Turque, Constantinople, 1790, s. 218.

35 Joseph von Priendl, Grammaire Turque d'une Toute Nouvelle Methode d'apprendre, Berlin, 1791, s. 95.

36 Cosimo Comidas de Carbognano, Primi Principi della Gramatica Turca, Roma, 1794, s. 550.

37 Bu eserleri tanıtan şu iki makale faydalıdır: Musa Duman, "Türkiye Türkçesi'nin Tarihî Kaynaklarından Carbognano'nun Grameri ve İmlâ-Telaffuz İlişkisi Bakımından Önemi”, İlmî Araştırmalar: Dil, Edebiyat, Tarih İncelemeleri, 1, 1995, s. 95-106; Mehmet Gümüşk1lıç, "Viguier ve Elemens de la Langue Turque Adlı Eseri”, İlmî Araştırmalar, 10, 2000, s. 39-64. 
az /i/'li telaffuz kadar yaygın olmalıdır. Son hecenin /o/ yanında /u/, hatta /1/ ile de telaffuz edildiğini yine ilk olarak Viguier kaydetmiştir. İslambol telaffuzundan başka Íslambul telaffuzunun da kaydedilmesi /u/'lu şeklin de yaygınlaşmaya başladığını gösterir. Preindl'a göre Stambol şekli 18. yüzyılda hâlâ vardır. Carbognano'nun kelimeyi sadece Istanbul şeklinde kaydetmesi önemlidir, ama bu kayıttan kelimenin /i/ ile telaffuz edilmediği sonucuna ulaşılamaz.

\begin{tabular}{|c|c|c|}
\hline 18. yüzyll & Arap harfli imla & telaffuz \\
\hline Vaughan & - & İstanbol \\
\hline Clodius & استانتبول| & İstambol \\
\hline Holderman & & İstanbol \\
\hline & & Istamb1l \\
& & Istanb1l \\
& & Istambol \\
& & Istanbol \\
& & Istambul \\
& & Istanbul \\
& & İslambol \\
& & Islambul \\
\hline Preindle & & İstambol \\
\hline Carbognano & - & Istambol \\
\hline
\end{tabular}

\section{9. yüzyıl}

Jean Charles de Besse (1829)'de ${ }^{38}$ kelime Sztambol /Stambol/ ve Isztambul / İstambul/ olmak üzere iki şekildedir.

Arthur Lumley Davids (1832)’te ${ }^{39}$ Arap harfleri ile استانبول, Latin harfleri ile Istambol /İstambol/ olarak kaydedilmiştir.

Amedee Jaubert (1833)’te ${ }^{40}$ Arap harfli şekil استامبول, Latin harfli şekil Istamboul /İstambul/'dur. Metinde /1/ ünlüsü/e/ ile yazılmaktadır, bu sebeple/I/ ünlüsü /i/'ye karşı1lı gelir.

Guillaume Schroeder (1835)' de ${ }^{41}$ kelime Latin harfleri ile Isztambul /İstambul/ olarak kaydedilmiştir.

38 Jean Charles de Besse, Abrege de la Grammaire Turque, Pest, 1829, s. 91, 155.

39 Arthur Lumley Davids, A Grammar of the Turkish Language, London, 1832, s. 89.

40 Amedee Jaubert, Elements de la Grammaire Turke, Paris, 1833, s. 49.

41 Guillaume Schroeder, Grammaire Turque a l'usage des Français et Anglais Contenant en outre une collection d'idiotismes, de discours Familiers et un Vocabulaire eb Français, Turc et Anglais, Leipsic, 1835, s. 129. 
Artin Hindoğlu (1838)'nda ${ }^{42}$ kelimenin hem Arap harfli hem de Latin harfli iki kaydı vardır. Arap harfli kayıtlar استامبول ، اسلامبول, Latin harfli kayıtlar ise istambol/İstambol/ ve islambol/İslambol/'dur.

Charles Boyd (1842)' da $^{43}$ kelimenin hem Arap harfli hem de Latin harfli iki kayd1 vardır. Arap harfli kayıtlar استانبول ، استامبول , Latin harfli kayıtlar ise istanbol /İstanbol/, istambol /İstambol/'dur.

Xavier Bianchi (1843)'de ${ }^{44}$ kelimenin Arap harfli üç, Latin harfli iki kaydı vardır. Arap harfli kayıtlar استانبول ، استتبول ، اسلامبول , Latin harfli kayitlar istāmbol /İstâmbol/, islāmbol /İslâmbol/ olarak geçer.

Antoine Paulin Pihan (1847)'da 'استانبول , Latin harfleri ile Stamboul /Stambul/ş̧eklindedir.

Friedrich Heinrich Dieterici (1854)'de ${ }^{46}$ kelimenin hem Arap harfli hem de Latin harfli iki kaydı vardır. Arap harfli kayıtlar استانبول ، اسلامبول', Latin harfli kayitlar İslambul /İslambul/ ve İstambul/İstambul/'dur.

Burckhardt Barker (1854)'da 'استامبول , kelime Arap harfleri ile Latin harfleri ile istambul /İstambul/ şeklindedir.

Alexandre Timoni (1854)'de d8 kelime Arap harfleri ile استانبول, Latin harfleri ile istanboul /İstanbul/, istanbol /İstanbol/ olarak kaydedilmiştir.

Alexandre Chodzko (1854)' $\mathrm{da}^{49}$ sadece Latin harfleri ile kaydedilmiş olan Stambol /Stambol/ ve Istambol/İstambol/ telaffuzları geçer; metinde Stambol şekli daha yaygındır.

Charles Viotte (1856)'de ${ }^{50}$ kelime sadece Latin harfleri ile Istámbol /İstambol/ olarak kaydedilmiştir.

Nassif Mallouf (1863)'ta ${ }^{51}$ Arap harfleri ile استانبول, Latin harfleri ile istambol /İstambol/s şeklindedir. Ayrıca eserde islambol/İslambol/şekli de vardır.

42 Artin Hindoğlu, Hazine-i Lugat ou Dictionnaire Turc-Français, Vienne, 1838, s. $28,38$.

43 Charles Boyd, The Turkish Interpreter or a New Grammar of the Turkish Language, Paris, London, 1842, s. 19, 161.

44 Xavier Bianchi, Dictionnarie Francais-Turc, Paris, 1843, s. 339.

45 Antoine Paulin Pihan, Glossaire des mots Français tires de l'arabe, du Persan et Turc, Paris, 1867, s. 262.

46 Friedrich Heinrich Dieterici, Chrestomathie Ottomane Précédér de Tableaux Grammaticaux et suivie d'un Glossaire Turc-Français, Berlin, 1854, s. 90.

47 W. Burckhardt Barker, A Practical Grammar of the Turkish Language with Dialogues and Vocabulary, London, 1854, s. 5.

48 Alexandre Timoni, Guide de la conversation (grammaire, dialogues, vocabulaire) françaisturc, Paris, s. 29, 108.

49 Alexandre Chodzko, Le Drogman Turc Donnat les Mots et les Phrases les plus Necessaires pour la Conservation, Paris, 1854, s. 24, 36.

50 Charles Viotte, Grammaire turque courte et facile, Leipzig, 1856, s. 111.

51 Nassif Mallouf, Grammaire élémentaire de la langue turque, Paris, 1862, s. 46, 60. 
Theodore Zenker (1866)'de ${ }^{52}$ kelime Arap harfleri ile dört farklı şekilde kaydedilmiştir: استانبول ، استان بول ، استامبول ، اسلامبول. Kelime, Latin harfleri ile ISTAMBOL /İstambol/ olarak verilmiştir. Zenker, kelimenin Stambul kelimesi ile ilgili olduğunu belirtir. İslambol telaffuzu için de "İslam'ın hâkim olduğu yer" anlamını vermiştir.

Ambroise Calfa (1869)' da $^{53}$ kelime Latin harfleri ile Istambol /İstambol/ olarak kaydedilmiştir.

Charles Wells (1880)'te ${ }^{54}$ kelime Arap harfleri ile استانبول, Latin harfleri ile Istanbol /İstanbol/ şeklindedir.

Şemseddin Sami (1883)'de kelime Arap harfleri ile استانبول, Latin harfleri ile ystanbol /Istanbol/ şeklindedir. Sözlükte ayrıca Arap harfli اسلامبول , Latin harfli Íslambol şekli de vardır.

James Redhouse (1884)'ta ${ }^{56}$ kelime Arap harfleri ile استنانبول, Latin harfleri ile istànbòl /İstanbol/şeklinde kaydedilmiştir.

John Jacob Manissadjian (1893)'da 'd7 kelime Arap harfleri ile استانبول, Latin harfleri ile ystanbol/Istanbol/ş̧eklinde kaydedilmiştir.

Bu yüzyılda kelimenin Arap harfli imlasında bütün ünlüleri harf ile göstermek -Bianchi'deki bir önek dışında- bir imla kuralı hâline gelmiş gibidir. Jaubert, Hindoğlu, Boyd, Barker ve Zenker'de u'dan önce /b/'li telaffuz p harfi ile yazıya da aktarılmıştır; burada telaffuz imlayı değiştirmiştir: استامبول/

19. yüzyıldaki 20 çeviri yazılı metnin ikisinde, Sami ve Manissadjian'da, kelimenin ön seste /1/ ile telaffuz edildiği gösterilmişken çoğunluk /i/'li telaffuzu kaydetmiştir. Besse ve Chodzko'da Stambol, Pihan'da Stambul telaffuzları vardır. Besse'nin hem Stambol hem de İstambul telaffuzlarını kaydetmesi Stambol telaffuzunda yabanc1 etkisi olabileceğini düşündürmektedir. 19. yüzyılda ön seste yaygın telaffuz /i/ iledir. Timoni, Redhouse, Sami ve Manissadjian hariç 16 metinde Arap harfleri ile ب'den önce ن bulunsa da telaffuz Latin harfleri ile $/ \mathrm{m} /$ 'li olarak gösterilmiştir; yaygın telaffuz /b/'den önce /m/'lidir. Boyd ve Jaubert'de kaydı, telaffuzun imlayı değiş̧tirdiğini gösterir niteliktedir. Son hece ünlü-

52 Julius Theodor Zenker, Türkisch-Arabisch-Persisches Handwörterbuch, c. I, Leipzig, 1866, s. 36,50 .

53 Ambroise Calfa, Dictionnaire de poche Français-Turc, Paris, 1869, s. 1.

54 Charles Wells, A Practical Grammer of the Turkish Language, London, 1880, s. 63.

55 Şemseddin Sami, Kamus- Fransevi Türkçeden Fransızcaya Lugat (Dictionnaire Turc-Français), İstanbul, 1883, X, s. 93.

56 James Redhouse, A Simplified Grammar of the Ottoman-Turkish Language, London, 1884, s. 186.

57 John Jacob Manissadjian, Lehrbuch der Modernen Osmanischen Sprache (Mürşid-i Lisan-l Osmani), Stuttgart\&Berlin, 1893, s. 10. 
sü metinlerde 17 kere /o/, 7 kere /u/ ile kaydedilmiştir; 2 metinde ise hem /o/ hem de $/ \mathrm{u} /$ ile telaffuzun mümkün olduğu tespit edilmiştir. 19. yüzyılda son hecede Türkçeleşmiş /u/ bulunsa da /o/'lu telaffuz daha yaygındır. Bu yüzyılda İslambol şekli de vardır, 1 metinde /u/ ile İslambul olarak tespit edilmiştir.

\begin{tabular}{|c|c|c|}
\hline 19. yüzyıl & Arap harfli imla & telaffuz \\
\hline Besse & - & $\begin{array}{l}\text { Stambol } \\
\text { İstambul }\end{array}$ \\
\hline Davids & استانبول & İstambol \\
\hline Jaubert & استامبول & İstambul \\
\hline Schroeder & - & İstambul \\
\hline Hindoğlu & استامبول ، اسلامبول & $\begin{array}{l}\text { İstambol } \\
\text { İslambol }\end{array}$ \\
\hline Boyd & استانبول ، استامبول & $\begin{array}{l}\text { İstanbol } \\
\text { İstambol }\end{array}$ \\
\hline Bianchi & استانبول ، استنبول ، اسلامبول & $\begin{array}{l}\text { İstambol } \\
\text { İslambol }\end{array}$ \\
\hline Pihan & استانبول & Stambul \\
\hline Dieterici & استانبول ، اسلامبول & $\begin{array}{l}\text { İstambul } \\
\text { İslambul }\end{array}$ \\
\hline Barker & استامبول & İstambul \\
\hline Timoni & استانبول & $\begin{array}{l}\text { İstanbul } \\
\text { İstanbol }\end{array}$ \\
\hline Chodzko & - & $\begin{array}{l}\text { Stambol } \\
\text { İstambol }\end{array}$ \\
\hline Viotte & - & İstambol \\
\hline Mallouf & استانبول & $\begin{array}{l}\text { İstambol } \\
\text { İslambol }\end{array}$ \\
\hline Zenker & استانبول ، استان بول ، استامبول ، & İstambol \\
\hline Calfa & - & İstambol \\
\hline Wells & استانبول & İstambol \\
\hline Sami & استانبول ، اسلامبول & $\begin{array}{l}\text { Istanbol } \\
\text { İslambol }\end{array}$ \\
\hline Redhouse & استانبول & İstanbol \\
\hline Manissadjian & استانبول & Istanbol \\
\hline
\end{tabular}




\section{0. yüzyıl}

V. Hovhannes Hagopian (1907)' da ${ }^{58}$ kelime Arap harfleri ile استانبول, Latin harfleri ile istambul /İstambul/ ve istambol/İstambol/ olarak kaydedilmiştir..

Ali Ulvi Elöve (1921) 59 /b/, /p/ ünsüzlerinden önce /n/ > /m/ değişmesi oldu-

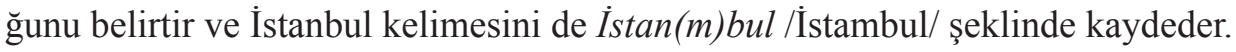

20. yüzy1lda kelime ön seste /i/ ile kaydedilmiştir. Telaffuzda iki eserde de /b/'den önce /m/ vardır. Hagopian, son hecede /u/ yanında /o/'lu telaffuzu da kaydetmiştir.

\begin{tabular}{|c|c|c|}
\hline 20. yüzyıl & Arap harfli imla & telaffuz \\
\hline \multirow{2}{*}{ Hagopian } & İstambul \\
& İstambol \\
\hline Deny & - & İstan(m)bul \\
\hline
\end{tabular}

İncelenen 38 çeviri yazılı metinde dördü sadece Viguier'de geçen 15 farklı İstanbul telaffuzu ${ }^{60}$ kaydedildikleri çeviri yazılı metinlere göre şöyledir:

1. /Stambol/ = ftambol: Schiltberger (1394-1427), Argenti (1533), Georgieviz (1553), Ferraguto (1611), Megiser (1612), Harsany (1672), Prindle (1791), Besse (1829), Chodzko (1854)

2. /Stambul/ = Stamboul: Pihan (1847)

3. /İsdambol/ = Isdambol: Molino (1641)

4. /İstambol/ = iftāmbol: Meninski (1680), Clodius (1730), Prindle (1791), Davids (1832), Hindoğlu (1838), Boyd (1842), Bianchi (1843), Chodzko (1854), Viotte (1856), Zenker (1866), Calfa (1869), Wells (1880), Hagopian (1907)

5. /İstambul/ = Istamboul: Jaubert (1833), Schroeder(1835), Dieterici (1854), Barker (1854), Besse (1829), Hagopian (1907), /Elöve (1941)/, /Ergenç (1995)/

6. /İstanbol/ = iftanbol: (Meninski 1680), Vaughan (1709), Holderman (1730), Boyd (1842), Timoni (1854), Wells (1880), Redhouse (1884)

7. /İstanbul/ = istanboul: Mascis (1677), Timoni (1854)

8. /İslambol/ = İslāmbol: (Meninski 1680), Viguier (1790), Hindoğlu (1838), Bianchi (1843), Zenker (1866)

58 V. Hovhannes Hagopian, Ottoman-Turkish Conversation-Grammer, London, 1907, s. 9, 79.

59 Jean Deny, Grammaire de la Langue Turque (Dialecte Osmanl), [Türk Dili Grameri (Osmanl Lehçesi)], Paris, 1921, (çev. Ali Ulvi Elöve, İstanbul 1941), s. 141.

60 Stachowski ve Woodhouse, Meninski (1680)'ye dayanarak ön seste a ile telaffuz edilen Astanbul şeklini de gösterirler, fakat onların referans olarak gösterdikleri 176 ve 205. sayfalarda Astanbul telaffuzuna rastlanamamıştır. 
9. /İslambul/ = Íslamboul: Viguier (1790), Dieterici (1854)

10. /Istamb11/ = Eftambel: Viguier (1790)

11. /Istanb11/ = eftanbel: Viguier (1790)

12. /Istambol/ = eftambol: Viguier (1790), Carbognano (1794)

13. /stanbol/ = eftanbol: Viguier (1790), Sami (1883), Manissadjian (1893)

14. /Istambul/ = eftamboul: Viguier (1790)

15. /Istanbul/ = eftanboul: Viguier (1790) 


\section{Sonuç}

16. yüzyıldan 20. yüzyılın başlarına kadar İstanbul kelimesi 15 farklı şekilde telaffuz edilmiştir. Bu çeşitliliği belirleyen sebepler, ön seste ünlünün bulunmaması veya /i-/, /1-/ ünlülerinin bulunmas1; ب’den önceki ن’un /n/ veya /m/ ve son ünlünün /o/, /u/ veya nadiren /1/ olarak telaffuz edilmesidir.

Asli şekle en yakın olan ve ön seste ünlü bulundurmayan Stambol şekli 15. yüzyıldaki Schiltberger ve 1533, 1553 tarihli metinlerden itibaren görülür -Stahowski ve Woodhouse'a göre bu Türkçedeki ilk şekildir.- ve Stambol telaffuzunun son kayıt tarihi 1791'dir. Son hecedeki ünlünün daralması ile oluşan -son hece ünlüsü bakımından daha da Türkçeleşmiş- Stambul şekli tek telaffuz örneği olarak 1847'de kaydedilmiştir. Kayıtlara göre Stambol ve Stambul şekillerinin 19. yüzyılın ortalarında da belirli bir kesim tarafindan telaffuz edildiği söylenebilir.

Çeviri yazılı metinler 15 . yüzyılın sonunda yazılmaya başlandı̆̆ı için bu yüzyıldan önce kelimenin ön sesi hakkında sadece Arap harfli metinlerdeki elifli yazılışa bakılarak tahminlerde bulunulabilir. Çeviri yazılı metinlere göre ön seste ilk telaffuz edilen ünlü /i/ ünlüsüdür; kelimenin bu ünlü ile başlayan 7 farklı telaffuzu vardır: Ísdambol, İstambol, Istanbol, Istambul, İstambol, İstanbul, İslambul. Ön seste telaffuz edilen diğer ünlü /1/ ünlüsüdür ve /1/'l1 telaffuz ilk olarak 18 . yüzyılın sonunda, 1790 yılında kaydedilmiştir. Bu ünlü ile başlayan ve 4'ü sadece Viguier'de geçen 6 farklı telaffuz vardır: Istambıl, Istanbıl, Istambol, Istanbol, Istambul, Istanbul.

Orta hecede yer alan ب'den önceki ن, 15 farklı kaydın 10’unda /m/ olarak telaffuz edilmiştir. Osmanlı Türkçesi döneminde /m/'li telaffuz o kadar yaygındır ki 19. yüzyıldaki 5 metinde kelime Arap harfleriyle de ن ile değil م ile استامبول/ şeklinde yazılmıştır. İclal Ergenç'e göre kelime Türkiye Türkçesinde de İstambul şeklinde telaffuz edilir. ${ }^{61}$

İstanbul adının son hecesinin /o/ ile telaffuzu asıl şekle yakın olandır ve 15 telaffuzun 7'sinde son hecede /o/ vardır. İlk metinlerden itibaren telaffuz kayıtları /o/ iledir ve /o/'lu son kayıt 1907 yılındadır. /o/'nun /u/'ya daralmasıyla Türkçeleşme süreci tamamlanan /u/'lu telaffuz, ilk olarak $1677^{\prime}$ 'de kaydedilmiştir ve 15 telaffuzun 6'sı /u/'ludur. Son hecenin /1/ ile telaffuz edildiği iki örnek 1790 y1lında kaydedilmiştir. Istambıl ve Istanbıl telaffuzlarında son hece ünlüsü -çift dudak ünsüzünün yanında bulunsa da- o $>\mathrm{u}>1$ değişimleri ile dudak uyumuna bağlıdır.

1533-1907 arasında ön seste yaygın olarak telaffuz edilen ünlü /i/'dir, ب’den önceki ن ن/m/ olarak ve son hecedeki ünlü de yaygın olarak /o/ ile telaffuz edil-

61 İclal Ergenç, Konuşma Dili ve Türkçenin Söyleyiş Sözlü̆̆̈̈: Bir Deneme, Simurg Yayınları, İstanbul, 1995, 37. 
miştir. $\mathrm{Bu}$ üç tespite göre Osmanlı Türkçesinde en yaygın telaffuz, 12 eserde kaydedilmiş olan Istambol şeklidir ve bu telaffuzun 1907 yılında da duyulduğu tespit edilmiştir. İstambol telaffuzundan sonra yaygın olan telaffuzlar İstanbol (6), Ístambul (5) ve Stambol (5)'dur. 


\section{Kaynakça}

Adamoviç, Milan, Floransalı Filippo Argenti'nin Notlarına Göre (1533) 16. Yüzyıl Türkçesi, çev. Aziz Merhan, Ankara, TDK, 2009.

Barker, W. Burckhardt, A Practical Grammar of the Turkish Language with Dialogues and Vocabulary, London, 1854.

Berberian, H., "Stanbol (İstanbul) Kelimesinin Etimolojisine Dair Bir Deneme", Ikktisat Tarihi Dergisi, 6/9, İstanbul, 1954.

Besse, Jean Charles de, Abrege de la Grammaire Turque, Pest, 1829.

Bianchi, Xavier, Dictionnarie Francais-Turc, Paris, 1843.

Boyd, Charles, The Turkish Interpreter or a New Grammar of the Turkish Language, Paris, London, 1842.

Calfa, Ambroise, Dictionnaire de poche Français-Turc, Paris, 1869.

Carbognano, Cosimo Comidas de, Primi Principi della Gramatica Turca, Roma, 1794.

Chodzko, Alexandre, Le Drogman Turc Donnat les Mots et les Phrases les plus Necessaires pour la Conservation, Paris, 1854.

Clodius, Johannes Christianus, Compendiosum lexicon latino-turcico-germanicum, Leipzig, 1730.

Dankof, Robert-Kahraman, Seyit Ali-Dağl1, Yücel, Evliya Çelebi Seyahatnâmesi, 1. kitap, İstanbul, Yap1 Kredi Yayınları, 2006.

Davids, Arthur Lumley, A Grammar of the Turkish Language, London, 1832.

Deny, Jean, Grammaire de la Langue Turque (Dialecte Osmanli), /Türk Dili Grameri (Osmanlı Lehçesi)/, Paris, 1921, çev. Ali Ulvi Elöve, İstanbul, 1941.

Dieterici, Friedrich Heinrich, Chrestomathie Ottomane Précédér de Tableaux Grammaticaux et suivie d'un Glossaire Turc-Français, Berlin, 1854.

Duman, Musa, "Türkiye Türkçesi’nin Tarihî Kaynaklarından Carbognano'nun Grameri ve İmlâ-Telaffuz İlişkisi Bakımından Önemi”, İlmî Araştırmalar: Dil, Edebiyat, Tarih Incelemeleri, 1, 1995.

Ergenç, İclal, Konuşma Dili ve Türkçenin Söyleyiş Sözlüğü: Bir Deneme, İstanbul, Simurg Yayınları, 1995.

Georgieviz, Bartholomeo, De Turcarum Moribus Epitome, Lvgdvni, Apvd Ioan Tornaesivm, 1557.

Grelot, Josephus, İstanbul Seyahatnamesi, çev. Maide Selen, Pera Turizm ve Ticaret AŞ, İstanbul, Alâattin Eser Kitaplığı Yayınları, 1998.

Gümüşk1lıç, Mehmet, "Viguier ve Elemens de la Langue Turque Adlı Eseri”, İlmî Araştırmalar, 10, 2000. 
Hagopian, V. Hovhannes, Ottoman-Turkish Conversation-Grammer, London, 1907.

Hazai, George, Das Osmanisch-Türkische im XVII. Jahrrhundert Untersuchun-gen an den Transkriptionstexten von Jakab Nagy de Harsany, Budapest, Akademiai Kiado, 1973. 1838.

Hindoğlu, Artin, Hazine-i Lugat ou Dictionnaire Turc-Français, Vienne,

Holderman, Jean Baptiste Daniel, Grammaire Turque, Constantinople, 1730.

İnalc1k, Halil, “İstanbul”,TDVIA, c. 23, İstanbul, 2001.

Jaubert, Amedee, Elements de la Grammaire Turke, Paris, 1833.

Kartallığlu, Yavuz, Söz Kitabı Türkçe-İtalyanca Sözlük, Bernardo da Parigi, Ankara, TDK, 2015.

Macit, Muhsin, Nedim Divant, ekitap, Kültür Bakanlığ1, 2012. (http://ekitap. kulturturizm.gov.tr/Eklenti/10635,nedim-divanipdf.pdf?0).

Mallouf, Nassif, Grammaire élémentaire de la langue turque, Paris, 1862.

Manissadjian, John Jacob, Lehrbuch der Modernen Osmanischen Sprache (Mürşid-i Lisan-ı Osmani), Stuttgart\&Berlin, 1893.

Mascis, Antonio, Vocabolario Toscana e Turchesco, Florence, 1677.

Megisero, Hieronymo, Institutionum Lingva Tvrcica, Leipzig, 1612.

Meninski, François Mesgnien, Thesaurus Linguarum Orientalium, Turciace, Arabiace, Persiace Lexicon, c. I, Stanislaw Stachowski-Mehmet Ölmez, İstanbul, Simurg, 2000.

Mont, Jean du, A New Voyage to the Levant 1690-1691, London, 1696.

Pihan, Antoine Paulin, Glossaire des mots Français tires de l'arabe, du Persan et Turc, Paris, 1867.

Priendl, Joseph von, Grammaire Turque d'une Toute Nouvelle Methode d'apprendre, Berlin, 1791.

Redhouse, James, A Simplified Grammar of the Ottoman-Turkish Language, London, 1884.

Rocchi, Luciano, Il "Dittionario della Lingua Turchesca" di Pietro Ferraguto (1611), Trieste, Edizioni Universita di Trieste, 2012.

Sami, Şemseddin, Kamus-ı Fransevi Türkçeden Fransızcaya Lugat (Dictionnaire Turc-Français), İstanbul, 1883.

Schiltberger, Johannes, Als Sklave im Osmanischen Reich und bei den Tataren: 1394-1427, Türkler ve Tatarlar Arasında, çev. Turgut Akpınar, İstanbul, 1997. 
Schroeder, Guillaume, Grammaire Turque a l'usage des Français et Anglais Contenant en outre une collection d'idiotismes, de discours Familiers et un Vocabulaire eb Français, Turc et Anglais, Leipsic, 1835.

Siemieniec-Golaś, Ewa, Turkish Lexical Content in "Dittionario Della lingua Italiana, Turchesca” by Giovanni Molino (1641), Kraków, 2005.

Stachowski, Marek-Woodhouse, Robert, "The Etymology of İstanbul: Making Optimal Use of the Evidence", Studia Etymologica Cracoviensia, vol. 20, Krakov, 2015.

Timoni, Alexandre, Guide de la conversation français- turc, Paris, 1854.

Vaughan, Thomas, A Grammar of the Turkish Language, London, 1709.

Viguier, Pierre François, Élémens De La Langue Turque, Constantinople, 1790.

Viotte, Charles, Grammaire turque courte et facile, Leipzig, 1856.

Wells, Charles, A Practical Grammer of the Turkish Language, London, 1880 .

Wheler, George, A Journey into Greece 1675-1676, London, 1682.

Yavuz, Kemal-Saraç, M. A. Yekta, Âşık Paşazade Osmanoğulları'nın Tarihi, İstanbul, Koç Kitaplığ $1,2003$.

Yavuzarslan, Paşa, Şemseddin Sami Kamus-ı Türki, Ankara, TDK, 2010.

Zenker, Julius Theodor, Türkisch-Arabisch-Persisches Handwörterbuch, c. I, Leipzig, 1866. 